\title{
Cross-Cultural Collaboration in ICT Procurement
}

\author{
Vibeke Dalberg \\ Det Norske Veritas (DNV) \\ NO-1322 Høvik \\ Norway \\ +4767578690
}

vibeke.dalberg@dnv.com

\author{
Endre Angelvik \\ Dag Runar Elvekrok \\ Det Norske Veritas (DNV) \\ NO-1322 Høvik \\ Norway
}

\author{
Asle Kristian Fossberg \\ Politiets data- og materielltjeneste \\ NO-0030 Oslo \\ Norway
}

\begin{abstract}
This paper describes a case study on cross-cultural collaboration in the European Union on the requirements and design phase of a common ICT procurement project, impacting each participating country. Based on this study, a cross-cultural risk assessment framework is proposed.
\end{abstract}

\section{Categories and Subject Descriptors}

K.6.1 [Management of Computing and Information Systems]: Project and people management - Life cycle, Systems analysis and design, Systems development ; K.6.3 [Management of

Computing and Information Systems]: Software management

Software development, Software selection

\section{General Terms}

Management, Design, Human Factors.

\section{Keywords}

Global Software Work, cross-cultural collaboration, procurement, ICT, international projects, European Union, Schengen.

\section{INTRODUCTION}

In Europe today there are several international political arenas with a large amount of collaboration and integration across national borders. The European Union (EU) and Schengen are two of these arenas. The policy and rule issues are negotiated and decided on a political level, but require an operational implementation across the EU/Schengen and the countries.

The study described in this paper investigates the impact of cultural differences on cross-cultural work, in the context of an international ICT procurement project.

The purpose of the study is to identify key work process areas, goals, questions, and metrics that can help assessing for a risk management purpose. The case study has resulted in a goal based assessment, with the objective of clarifying cultural-related risks in an international project. It is anticipated that through using the assessment, the likelihood of achieving the goals of the project and the different nations involved can be strengthened.

Permission to make digital or hard copies of all or part of this work for personal or classroom use is granted without fee provided that copies are not made or distributed for profit or commercial advantage and that copies bear this notice and the full citation on the first page. To copy otherwise, or republish, to post on servers or to redistribute to lists, requires prior specific permission and/or a fee.

GSD'06, May 23, 2006, Shanghai, China.

Copyright 2006 ACM 1-59593-085-X/06/0005...\$5.00.
This paper is outlined as follows: First we give a background overview on cross cultural globally distributed software work. Section 3 looks into the case and the research method used in this study. In the following section the case findings are elaborated, and in section 5 the findings are analyzed, resulting in the crosscultural risk assessment framework presented in section 6. Section 7 concludes and looks at further work.

\section{BACKGROUND}

This section introduces some important aspects of global software work and cross-cultural collaboration for the further analysis. A framework for ICT procurement is also introduced.

\subsection{Cross-cultural globally distributed software work}

Work on software related issues is complex organisational work. It is a network of interaction between people, organisation and technology, involving a variety of social and human issues, such as relationships of people, teams, organisations and nations with different backgrounds, spoken languages and styles of working. Complex software work is knowledge intensive, communicationand collaboration-dependent activities that in high degree are based on tacit and intangible knowledge. Intangibility, heterogeneity, mobility and scalability are features that differentiate software work from other services and also manufacturing activity.

Globally distributed collaborative software work emerges in different contexts and from different motivation. Global Software Work (GSW) is defined as software work undertaken at geographically separated locations across national boundaries in a coordinated fashion involving real time or asynchronous interaction [14]. GSW can include work done across national borders through outsourcing, alliances, subsidiary arrangements or purchase. The case study presented in this paper is a project where the partners are on equal level, but geographically distributed across European nations.

A cross-cultural globally distributed setting magnifies the complexities of collaborative work on software, creating new and changing existing challenges.

The experience of many business projects, and the conclusion of various research work is that working across cultures on this type of work is a challenging process. A lot of research has been performed, but viewing it as a multidisciplinary field in regards to manage the risks magnified by this, seems to be not particularly researched. 
Different people give different meanings to a situation based on their socio-cultural background, which can lead to conflict [16]. Culture can have a huge effect on how people interpret and react to a situation. Being aware of this in order to manage the risks and possible opportunities derived from such a situation will be necessary.

Research on culture is not a new science but has until the late 1020 years largely been addressed within the scope of anthropology, as among others recognised in the work found in [7], [8], [9]. Anthropology does however largely look at single cultures in isolation. Studies on cross-cultural aspects have however increased in numbers with the internationalisation of business and work environments. Still, international business literature seems to be dominated by classical marketing, organisational and management theories. As Hofstede [10] studied the cross-cultural dimensions of IBM in different countries, the attention turned to cross-cultural operation and work. This line has been followed up by among others by Trompenaars and Hampden-Turner [15] as the most cited one. A popular assertion is that the cross-cultural dimension is a source of creativity, because of the differences of the people brought together. This fits well with the idea of the knowledge-creating company suggested by Nonaka and Takeuchi [11] but still Hofstede [10] argues that the cross-cultural differences are much more commonly a source for conflicts rather than creativity.

The differences also mean that people of different cultures have different understanding of what good teamwork implies and how to approach it. Omitting the question of what 'good' teamwork ought to be for a while, all types of teamwork imply some parameters (fundamentals) that need to be solved independent of culture. These can be derived from [10] and [15]: Relation to the task to perform, Relation to time, Relation to others, Decision making, and Communication style.

These parameters are universal for all kinds of work, but different cultures put their own flavours on them, which can easily be misunderstood by "outsiders". When collaborating, this creates some particular challenges.

Large-scale projects executed in an international setting involve a number of partners that have different experiences in working cross-culturally and that are motivated by a range of conflicting goals and interests. Knowledge about the partner is important in order to make qualified choices, before and during the execution phase. Efficient collaboration results from differences that are understood, managed and reconciled. Assessing the partners' experiences, interests, preferences and abilities in terms of risk management, will make the project more efficient..

All kinds of collaboration are challenging, even within one culture. Culture can be defined at different levels, for example a national culture, an organisational culture, or an internal group culture. The guiding principle is that the challenges scale up as the differences become larger. Thus, the more differences the more challenging cooperation. This is in this paper seen in the term of risk management. The more challenges, i.e. differences, the greater the risks imposed to the cooperation. An assessment and a subsequent analysis on the cross-cultural collaboration will help in the process of managing the risk.

\subsection{GQM}

The cross-cultural risk assessment presented in this paper is an add-on to a larger project on developing the ICT Procurement Capability Model (IPCM ${ }^{\mathrm{TM}}$ ) (see [4]). The IPCM ${ }^{\mathrm{TM}}$ defines Key Process Areas (KPAs) that contains support for the following three usage areas:

\section{- Capability Determination}

- Risk Management

- $\quad$ Process Implementation

The Goal-Question-Metric (GQM, see [5]) paradigm is used to describe goals within each KPA. There are also suggested questions and metrics to be used in assessment of goal fulfilment.

The risk assessment presented here focuses specifically on managing culture related risks when establishing common specifications for procurement projects. The assessment also adheres to the GQM structure used in the IPCM ${ }^{\mathrm{TM}}$, and defines goals as well as suggesting questions and metrics to be used when carrying out an assessment.

\section{RESEARCH METHODS}

This section describes the studied case, and how information was elicited and later analyzed based on the case

\subsection{The case}

The case is an EU project with 25 equal partners (Schengen countries), together developing one central software solution, and each developing own national software that is going to exchange data with the central system. This will replace the existing system, adding extra functionality, which requires that all the countries agree on the functional and technical requirements to and design of the central system. This will have large implications on the design of the national systems. The experience is that gaining an agreement between 25 equal actors is a huge challenge.

There is one central project, run by the European Commission, where each Schengen member country is represented. This is where the central software solution is designed and developed. Each country has their own national project, designing and developing their national software. Each country has own laws, practice, finance, preferences and history that set their requirements to the system. In short, there are a number of different cultures that has to agree on one common solution. The requirements of the central project have the highest priority, and thus it is of major importance to include as many own requirements as possible into the central project.

This case study is based on one of the countries' (Norway) views on the requirement and design phase of the project. Norway and Iceland are members of Schengen, but not of EU, which means they have the rights to speak, but not vote in the requirement negotiations in this project. Therefore, these states have decided to initiate an informal collaboration group of five countries, in order to have a stronger influence on the decision making in the central project. This is the same tactic as Norway used with success in a previous Schengen software development project. Some of the other countries have created similar groups, while others have decided to work on their own. See figure 2 for illustration, where $[\mathrm{A}-\mathrm{H}]$ represents the national teams, $[\mathrm{B}-\mathrm{D}]$ the informal collaboration group, and the lines are illustrating the relations. 


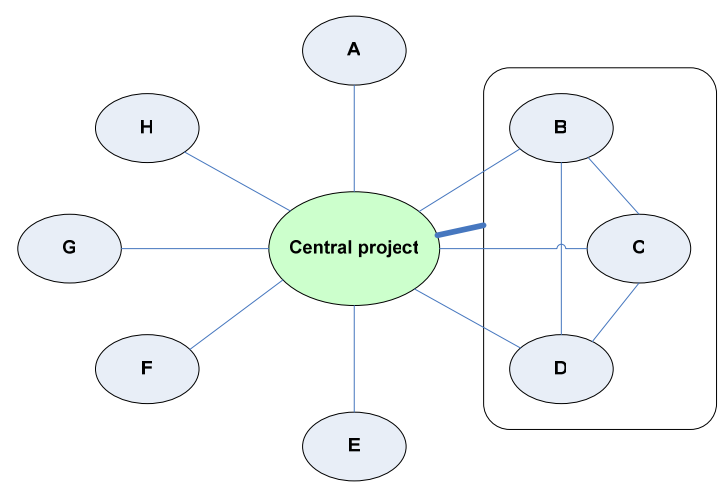

Figure 1. Case project setup

\subsection{Information elicitation}

The development of the cross-cultural risk assessment framework is based on a multi-method approach, including interviews, document studies, survey and an in-depth case study have been used. All individual pieces of evidence collected have been registered in an evidence file.

A number of interviews have been performed: First, a single interview with the main objective of gaining an overall organizational overview for the researchers, using an interview guide. Secondly, further persons have been presented to a webbased questionnaire that asked them to fill in experience details. The persons were selected by the first person interviewed, where we specifically asked for experienced individuals, but with different roles/perspectives. The use of an unscheduled web-based survey reduced the need for scheduled time for a second set of focused interviews, based on interview guide.

Based on the interview framework from the development of the IPCM $^{\mathrm{TM}}$, and initial meetings with the case organization, an interview guide focusing on cross-cultural risks was established.

The interviews were semi-structured, following topics of this interview guide. The topics and associated questions were openended in order to allow exploration. The interviews were taped and scripted. These scripts became part of the overall evidence file. The persons are considered some of the most senior by their own organization in this area, and have worked in several similar projects. The way we have conducted investigation is based on reviewed interview guides, and initial analysis of results have taken place soon after data collection.

\subsection{Information analysis}

The interview scripts were analyzed and compared to existing literature on cross-cultural and global software development issues.

Recurring patterns have been sought for by the research team through repeatedly iterating over all evidences gathered. Attention has been paid not only to what has been found, but also the quality of the source of the evidence. The findings were analyzed towards existing literature on cross-cultural collaboration.

Based on this analysis, best practices and results have been structured through using the Goal-Question-Metric (GQM) paradigm [5] to give guidance and support for risk assessments.

\subsection{List of instruments}

In this section, instruments used in this research are briefly described.

Table 1. List of instruments

\begin{tabular}{|l|l|}
\hline ID & Description \\
\hline I1 & $\begin{array}{l}\text { Web- based survey - experience details gathering for all } \\
\text { interviewed persons. }\end{array}$ \\
\hline I2 & $\begin{array}{l}\text { Interview guide with main purpose of getting an } \\
\text { overview of the organization and its procurement } \\
\text { process. }\end{array}$ \\
\hline I3 & $\begin{array}{l}\text { Interview guide with the purpose of understanding the } \\
\text { cultural risks in an international collaboration on } \\
\text { common ICT procurement. Anonymity was ensured. }\end{array}$ \\
\hline I4 & $\begin{array}{l}\text { Evidence file, where each evidence has been assigned an } \\
\text { identifier. }\end{array}$ \\
\hline
\end{tabular}

\subsection{Threats to validity}

To reduce the threat of various mono-bias versions, there have been two researchers conducting the interviews, with crossing over between researcher/partners when possible.

\section{FINDINGS}

In this section, we present individual pieces of findings identified in the interviews.

\subsection{The central project}

The central project develops the central Schengen software system. Meetings including delegates from each country are conducted regularly through different forums (formal meetings, workshops etc.). All members of Schengen have the right to speak, but only those who are members of EU have the right to vote. The number of votes each country has is different.

The oldest Schengen countries hold the highest status. Newer Schengen members tend to support the views of larger countries, rather than pursuing their own immediate interests directly. The Norwegian team believes that trust and status should be built based on knowledge, and that the actor possesses opinions and are willing to fight for them. In the central project meetings, the speakers are logged. These logs are sent to a high level in the EU, and status is given those who are on the speakers list. This is of different importance to the participating countries and influences the quality of the contributions made in the central project meetings.

The political system and the arrangement of the national Police differ from country to country. Some have a more complex system than others, with several different polices. The home country domain knowledge is therefore varying between the actors.

Some countries are less hierarchical than others, and this is often manifested through differences in the national decision processes and the authority of the delegates. The Norwegian delegates have extended decision authorities, while others have to run the decisions upward in their national hierarchy. The Norwegian team reports to a relatively flat national hierarchy, with easy access to the steering group, director of the police and the ministry. The Norwegian team sees the risk in possible future national political 
or bureaucratically changes, or changes in the central project towards a more formal and less flexible regime.

System development methods, as well as project management methods vary considerably among the different countries. This is experienced as challenging for the collaboration.

In the informal group English is the common language, and is spoken by everyone. English is also the common language in the central project, but some countries require an interpreter. Not everyone is fluent in English, but it is said that it is accepted, and that the project speak "Schenglish". The dress code in the meetings has always been formal, but it has softened after the new countries have joined Schengen.

The countries have different priorities towards the development of the new system. The old countries already have a working system, but new countries do not have a system, and is dependent on having one before they can become a full member of Schengen. The time aspect is thus clearly the most important for the new countries. Norway, being one of the older members prioritizes quality highly, argues that the project should spend the necessary time and resources in order to reach the wanted quality.

\subsection{The informal collaboration group}

Norway's motivation for joining the informal collaboration group was first of all a desire to actively contribute to the success of the central and national projects, even though they do not have rights to vote. In a small group it is easier to discuss own issues than in a larger and formal group. The informal collaboration group believes that they can ensure more impact by collaborating through this smaller group.

The Norwegian team believes in focusing on new technology for the software solution, not using any of their old system. When finding allies for this group collaboration, their far most important requirement to the partner was that they shared their view on technology issues. Personal chemistry and previous experience of collaboration was also important when the group was formed.

The group meets regularly and discusses issues and how to bring them to the central project. Often they write documents, and distribute to other countries, trying to convince them to join them in this requirement in the next meeting in the central project. They have learned that if they impose their requirements in a written, formal form, it is much easier to get them accepted.

The Norwegian team members interviewed claimed that the group has a rational approach to decision making, where the conversations are straight forward and to the point.

Through the group collaboration they learn from each other, and can discuss the national and central challenges on their own terms. In this way all the members increase their knowledge through collaboration. The intimacy of being a part of a group is also valued.

The Norwegian team members always focus on professional issues when meeting other project partners, also during breaks and meals. When meeting in the central project, they are networking with other members than their established group. They regard it as very important to get to know the right actors, which are those who possess power and votes.

\section{ANALYSIS}

In this section we analyze the combinations of findings of the case study and existing literature, concluding in the dimensions used in the cross-cultural risk assessment framework presented in the next section.

As indicated in section 2.1 cross-cultural teamwork may be regarded along some particular dimensions or, as noted here, parameters. These may be regarded as general and are independent of what kind of work or what the task to execute involves. It may be a simple information processing task performed from your desk or complex physical work in a construction plant involving a large number of workers. The parameters are independent of how many are involved, a couple of people or a large team of many thousand workers. Finally, they are independent of whether it is a single culture or cross-culture team.

The parameters have for this research acted as a guideline for designing a framework. The framework covers all the parameters but does not explicitly address them. The parameters do however make the foundation for the questions determining the teams' orientations. It is assumed that the more gaps there are in the different teams orientation, the greater the opportunities for conflict, misunderstandings and so on. Consequently, gaps are risks to the overall performance of the project as well as the agendas of the individual participants as they cannot easily read the map of orientation in this unfamiliar environment. The predictability and performance drop. The framework is developed to increase the predictability and thereby counteract the performance drop.

The project is relatively geographically distributed, but in the same time zone, and there is an increased effort to initiate contact, and trust is an issue.

Due to the international aspect of the case studied, culture is a natural parameter to focus. This covers typical cultural issues as recognized in Hofstede [10] and Trompenaars and HampdenTurner [15]. These dimensions aim at revealing differences in behavior, preferences and practices that can be traced back to different cultural origins. It is however many processes that apply to team work that not are reasonable to characterize in terms of cultural differences. This are covered in the dimension of collaboration and work processes.

In addition to review culture as an issue that may impose risk to the purposes of a national team, national political issues are likely to influence the project, work processes and decision making in different ways. Similar does the EU have its own political structure. Moreover, the efficiency of the project will largely be determined by the participants' domain knowledge. Domain knowledge does here refer to the area of application, which is the police and Schengen. It also includes that some nations have a more complex department or sector organization than others that they need to take into account when they propose their requirements to the main project. All factors like the abovementioned are here embraced in the term context. This gives the following dimensions of orientation, which we are using 
as a basis for the structuring of the cross-cultural risk assessment framework elaborated in the next chapter:

1. Collaboration and work processes

2. Cultural

3. Context

\section{RISK ASSESSMENT FRAMEWORK}

Based on the Goal-Question-Metric (GQM see [5]) structure we suggest a series of goals, questions and metrics for the CrossCultural Collaborative Public Procurement risk assessment framework.

By using the suggested set of goals, questions and metrics from, a user can perform an assessment of cross-cultural risk in the requirements work of the procurement project. The three dimensions of collaboration and work processes, cultural, and context are used as the dimensions of orientation.

Due to space limitations the complete set of questions and metrics for each goal are not included in this paper, only a short summary of the content. For detailed description on this cross-cultural ICT procurement risk assessment framework, see [4].

\subsection{Collaboration and work processes goals}

This section focuses on how the work and collaboration between equal partners is likely to be, addressing international experience, communication, commitment, trust, stability, priorities, confidence and risk of dissolving. The collaboration and work process goals are:

- Identification of partners' corresponding international experience: Focusing on international experience.

- Identification of communication skills and standards: Focusing on common language, time and space.

- Identification of the mutual connection within the group: Focusing on the commitment and dependency to the group, continuity and stability of the group, and the inner coherence of the group.

- Identification of trust and status within the group: Focusing on the factors for creating trust and status within the group.

- Identification of the partners' stability in functional and technical requirements: Focusing on the tendency to requirement stability.

- Identification of the partners' priorities related to the project: Focusing on what is regarded as most important (technology, functionality, time, cost, relationships, politics).

- Identification of the partners' relation to the main project: Focusing on the commitment, trust, confidence or opposition.

- Identification of risk if the informal group dissolve: Focusing on the risks for group dissolving.

\subsection{Culture goals}

This section focuses on the culture related goals, including task approach, relation to others and to time, visionary, decision making, and communication.

- Identification of the partners' approach to tasks: Focusing on a practical or theoretical, and single- versus multi-task oriented approach.
- Identification of the partners' way of relating to others: Focusing on the relationship orientation, and the important factors for establishing relationships.

- Identification of the partners' relation to time: Focusing on planning preferences and long- versus short-term.

- Identification of the partners' preferences for visionary solutions: Focusing on the tendency to future-orientation or historical restrains.

- Identification of the partners' decision making practise: Focusing on the mandate for decision-making, the importance of and basis for decision-making, group consensus, and the status of decision-makers.

- Identification of the partners' preferred way of communicating: Focusing on clarity and mediums for communication.

\subsection{Context goals}

This section includes goals on the partner's experience and competence within the application domain area, with political governed projects, on technology, and project management, as well as influential national political processes.

- Identification of the partners' competence and experience within the application domain area: Focusing on experience and formal training.

- Identification of the partners' competence and experience working with political governed projects: Focusing on experience, understanding and ability to predict.

- Identification of the partners' approach to project management: Focusing on use of project management method.

- Identification of the partners' approach to system development: Focusing on use of system development method.

- Identification of the partners' competence and experience on technical issues: Focusing on proper technological understanding.

- Identification of the partners' corresponding views on the project: Focusing on corresponding views on for example technology, requirements, and plans.

- Identification of political processes of the nations that may have consequences for the project execution: Focusing on the vulnerability towards political processes.

\subsection{Example Questions and Metrics}

To illustrate the complete GQM structure in the framework, the questions and metrics of the "Identification of the partners' way of relating to others" goal is included below.

Goal: Identification of the partners' way of relating to others. Question: To what extent does the partner seem to focus on relationships? ("yes" on metrics tends to relationship orientation)

- Metric: The partner seems to need time for building relations before going into detail discussion of the case in question

- $\quad$ Metric: The partner is likely to find trust and loyalty to be a result of long-term relationships, and something that not easily is achieved 
- $\quad$ Metric: Members with high skills of managing relations are also those with the most status and power in the group

- Metric: Members with several lateral relations are also those with the most status and power in the group

Question: What is the important factor for the establishing of relationships? (choose two)

- Metric: Technical knowledge is the most important factor for establishing relationships

- Metric: Personal chemistry is the most important factor for establishing relationships

- Metric: Lateral relations and important contacts are the most important factor for establishing relationships

- Metric: Knowledge of the politics are the most important factor for establishing relationships

- Metric: Application domain knowledge is the most important factor for establishing relationships

\subsection{Use of the framework}

The cross-cultural risk assessment will be based on the national team's own judgement of the project partners and situation. It can be used to evaluate the situation during project execution, or, upfront to help identifying reasonable partners and processes. Moreover, the scope of analysis may be expanded to include the partners or potential partners' own judgement of the others. This would add valuable information to the analysis moving from a single-side approach to a multi-side approach. Comparing these multi-side analyses and identifying the major differences will largely identify the risks of the cooperation. This gives the following steps and alternatives for the risk assessment:

Single-side analysis (all assessments done by national team)

- National team versus informal team

- National team versus main project

- Informal team versus main project

Multi-side analysis (each assessments involve the viewpoint of the different national teams)

- National team versus informal team

- National team versus main project

- Informal team versus main project

A multi-side analysis will include a comparison of the different analyses performed. Most questions are relevant for all alternatives.

It is noted that by changing the way the questions are asked, the analysis can be changed to a self-assessment from the partners' side (opposite to an assessment of each other which is the approach above). The same steps and comparisons will apply if this viewpoint is chosen.

\section{CONCLUSION AND FURTHER WORK}

The cross-cultural risk assessment framework presented in this paper is developed based on studies of an EU ICT procurement project. The study identified several important aspects of risks related to cross-cultural collaboration. And even though the results are based on a special context of equal partner collaboration in the public sector, the hypothesis is that this can be used for regular global software development projects as well.
Further work will firstly be to study other partners of the present case, secondly to study the validity of the framework towards other cross-cultural collaborative projects.

The framework considers large-scale project executed in a crosscultural setting. For the case studied, this is within the ICT industry. Through some minor adaptations the framwerok will easily apply for also other kinds of industries and projects. This will also be in the scope of further work.

We are currently planning a project where we will use the findings presented in this paper as one input. We will through this project to enable research-based and validated risk management of globally distributed software work. This will be done through identifying the parameters of the work context as well as the parameters of risk management that are affected by a globally distributed setting, and analyse their relations, in order to apply the best risk management to a given context. This research project will give an answer on whether and eventually how this can be done.

\section{ACKNOWLEDGMENTS}

We would like to thank Politiets data- og materielltjeneste for participating in this study.

\section{REFERENCES}

[1] Adler, N, 2001. International Dimensions of Organizational Behaviour. South-Western Publishing, ISBN 0324057865.

[2] Angelvik, Bratthall, Mestl, Stålhane It is Time to Increase the Focus on Software Acquisition. EuroSPI 2005

[3] Angelvik, Bratthall, Brovold, Handeland, Ullnæss Massive Outsourcing of ICT: Preparing the Buyer. First International Conference on Management of Globally distributed Work, Indian Institute of Management Bangalore, India, December 28-30 2005

[4] Angelvik, Bratthall, Mestl, Skramstad, Dalberg, Elvekrok The ICT Procurement Capability Model (IPCM $\left.{ }^{\mathrm{TM}}\right)$ version 1.00 contact the authors at Det Norske Veritas for more information

[5] Basili, V., Caldiera, G., Rombach, D. 1994. Goal/question/metric paradigm. In Encyclopedia of Software Engineering. Vol. 1, J. C. Marciniak, Ed. John Wiley and Sons, New York, 528-532.

[6] Davison, Canney S., 1996. Leading and Facilitating Internmational Teams. In DICM 2004, Workbook Three.

[7] Hall, Edward T. and Mildred Reed Hall, 1987. Hidden Differences: Doing business with the Japanese. Anchor Book

[8] Hall, Edward T. 1976. Beyond Culture. Anchor Book

[9] Hall, Edward T. 1959. Silent Language. Anchor Book

[10] Hofstede, Geert, 1993. Cultures and Organisations: Software of the Mind. McGraw-Hill, ISBN 0006377408.

[11] Nonaka, Ikujiro and Hirotaka Takeuchi. 1993. The Knowledge_creating Company. Oxford University Press.

[12] Ohmae, Kenichi, 1989. Managing in a Borderless World. In Transnational Management: Text, cases, and Readings in Cross-Border Management, Bartlett et al., 2004. 
[13] Perlmutter, H.V., 1969. The Tortuous Evolution of the Multinational Corporation. In Transnational Management: Text, cases, and Readings in Cross-Border Management, Bartlett et al., 2004.

[14] Sahay, Nicholson \& Krishna. Global IT Outsourcing: Software development across borders. Cambridge University Press 2003. ISBN 052181604.

[15] Trompenaars, Fons and Charles Hampden-Turner, 1998. Riding the Waves of Culture: Understanding Diversity in
Global Business. $2^{\text {nd }}$ Edition. McGraw-Hill, ISBN0786311258.

[16] Ågerfalk, Par J; Fitzgerald, Brian; Holmstrøm, Helena; Lings, Brian; Lundell, Bjørn; O Conchuir, Eoin. A Framework for Considering Opportunities and Threats in Distributed Software Development. DiSD 2005, $13^{\text {th }}$ IEEE Requirements Engineering Conference 2005, Paris, August 2005. ISBN 3-85403-193-9 